\title{
Mucoepidermoid Carcinoma of Palate - A Case Report and Review of Literature
}

\author{
Thakur Prerana, Srinivas Gadipelly, Pavan Kumar Batchu, Pratikshya Kothia \\ Department of Oral and Maxillofacial Surgery, Kamineni Institute of Dental Sciences, Narketpally, Telangana State, India
}

Email for correspondence: thakurprerana08@gmail.com

\begin{abstract}
Malignancy of salivary glands is rare and comprises $<3 \%$ of head and neck cancers. Mucoepidermoid carcinoma (MEC) is one of the most common salivary gland malignancies. MEC mainly occurs in the parotid gland, along with minor salivary glands being the second common site, particularly palate. MEC occurs most frequently between third and sixth decades of life and affects women more often than men, in the ratio of 3:2. The present case report highlights the need for the proper diagnosis and treatment plan in cases of MEC as it can lead to morbidity and mortality.
\end{abstract}

Key words: Minor salivary gland, mucoepidermoid carcinoma, surgical management

\section{INTRODUCTION}

Malignancies of the salivary gland are rare and comprise $<3 \%$ of head and neck cancers. ${ }^{[1]}$ Mucoepidermoid carcinoma (MEC) is a malignant epithelial tumor that arises from the pluripotent cells of excretory ducts of salivary gland epithelium. It was first described by Massao and Berger in 1924. ${ }^{[2]}$ Previously, it was termed as a mucoepidermoid tumor and was considered to be a benign lesion. The WHO in 1990 classified it as a malignant neoplasm and renamed it to MEC. ${ }^{[2]}$

Although it accounts for $<10 \%$ of all tumors of the salivary gland, it constitutes approximately $30 \%$ of all malignant tumors of salivary glands. ${ }^{[3,4]} \mathrm{MEC}$ occurs most frequently between the third and sixth decades of life and affects women more often than men, in a ratio of $3: 2 .^{[5]}$ It is frequently seen in the parotid gland, followed by minor salivary glands. Involvement of minor salivary glands is commonly seen in the region of the hard palate, soft palate, retromolar region, buccal mucosa, floor of mouth, and labial mucosa. The palate is the most frequent

\section{Quick Response Code Article Info:}

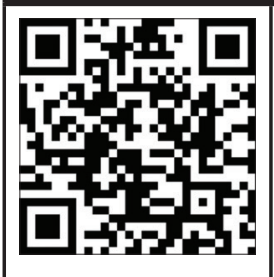

doi: 10.5866/2018.10.10197

Received: $25-09-2018$

Revised: $27-10-2018$

Accepted: $20-11-2018$

Available Online: 05-01-2019, (www.

nacd.in)@ NAD, 2019 - All rights reserved site for MEC (28\%), followed by the retromolar region $(23 \%)$, the floor of the mouth (14\%), the buccal mucosa (11\%), and the lower lip (9\%). ${ }^{[6]}$

The etiology of these tumors is obscure, but a number of risk factors have been keyed out including radiation exposure, tobacco use, genetic predisposition (translocation of the specific $[11 ; 19]$ [q21;p13] chromosomes is related with the occurrence of MEC), viruses, and environmental chemicals. ${ }^{[7-9]}$ MEC of hard palate presents as a slow-growing, persistent swelling which is usually painless and soft in consistency. However, pain with pus discharge through a sinus tract may be seen in the lesion with secondary infection. Ulceration, resorption of the underlying bone, numbness of adjacent teeth, tooth mobility, root resorption, and indurated/firm mass are indicators of advanced disease or high-grade MEC. Advanced disease and late diagnosis cause extensive spread, with the possibility of perforation of the hard palate and invasion into maxillary antrum or nasal cavity. Spread in the pterygoid region, maxillary antrum, nasal cavity, and the cranial base requires extensive surgical resection, thereby increasing the risk of post-operative morbidity and mortality. ${ }^{[10]}$

The present article reports a case of $\mathrm{MEC}$ involving hard and soft palate, presenting as persistent slow-growing ulcer, localized only to the palatal mucosa. The pathology was successfully treated by wide local excision under general anesthesia. 


\section{CASE REPORT}

A 50-year-old female patient reported to the Department of Oral and Maxillofacial Surgery, Kamineni Institute of Dental Sciences with a chief complaint of swelling in the upper right back tooth region since 9 months. The patient had difficulty in chewing and swallowing due to the swelling.

On extraoral examination, the face was apparently symmetrical and there was no sign of palpable lymph nodes. Intraorally, a solitary swelling was seen on the right posterior half of palate of size $1 \mathrm{~cm} \quad 1.2 \mathrm{~cm}$ approximately, extending anteroposteriorly from mesial of 17 to the junction of the hard and soft palate and mediolaterally from palatal gingiva to 0.8 $\mathrm{cm}$ away from mid-palatine raphae. Central ulceration is seen adjacent to 17 of size $7 \mathrm{~mm}$ $3 \mathrm{~mm}$ approximately [Figure 1]. The swelling was pinkish red in color. On palpation, the swelling was tender, firm in consistency, fixed to underlying structures, and no discharge were seen. Computed tomography revealed a wellcircumscribed lesion in the right palatal region without any signs of bony infiltration [Figure 2].

Incisional biopsy was performed under LA ( $2 \%$ lignocaine with 1:80,000 adrenaline) and was sent for histopathological examination. On microscopic examination, the connective tissue stroma showed the presence of atypical epidermoid and mucous cells, arranged in the form of a ductal island, cords, and strands. The epidermoid cells show dysplastic features such as nuclear and cellular pleomorphism, hyperchromatism, and increased nuclear-cytoplasmic ratio. Based on the above histopathological findings, the lesion was diagnosed as "low-grade MEC."

Wide local excision with $1 \mathrm{~cm}$ tumor-free margins of soft tissue was done under GA [Figure 3]. The lesion was excised down to the periosteum while sparing the palatine bone, as the lesion was encapsulated and no bony involvement was seen and the specimen was sent to the histopathological investigation. After excision of lesion bactigauze, chlorhexidine gauze dressing was placed and covered with an acrylic plate [Figure 4].

Follow-up of the patient was done. After 1 month acrylic plate was removed and formation of granulation tissue was observed, after 3 months healing was improved, and at 6 months healing was satisfactory, and phonetics was improved [Figure 5].

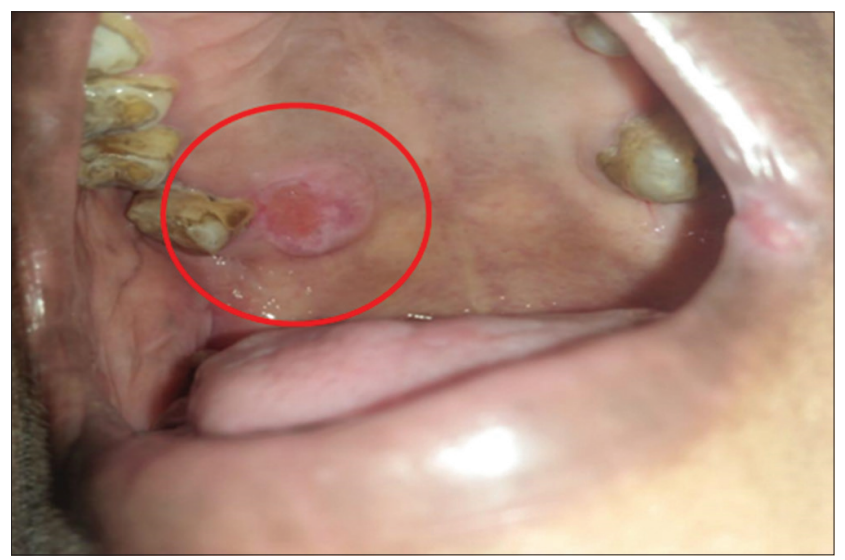

Figure 1: Clinical picture showing a solitary swelling on the right posterior half of palate of size $1 \mathrm{~cm} 1.2 \mathrm{~cm}$ approximately, extending anteroposteriorly from mesial of 17 to the junction of the hard and soft palate and mediolaterally from palatal gingiva to $0.8 \mathrm{~cm}$ away from mid-palatine raphae. Central ulceration seen adjacent to 17 of size $7 \mathrm{~mm} 3 \mathrm{~mm}$ approximately

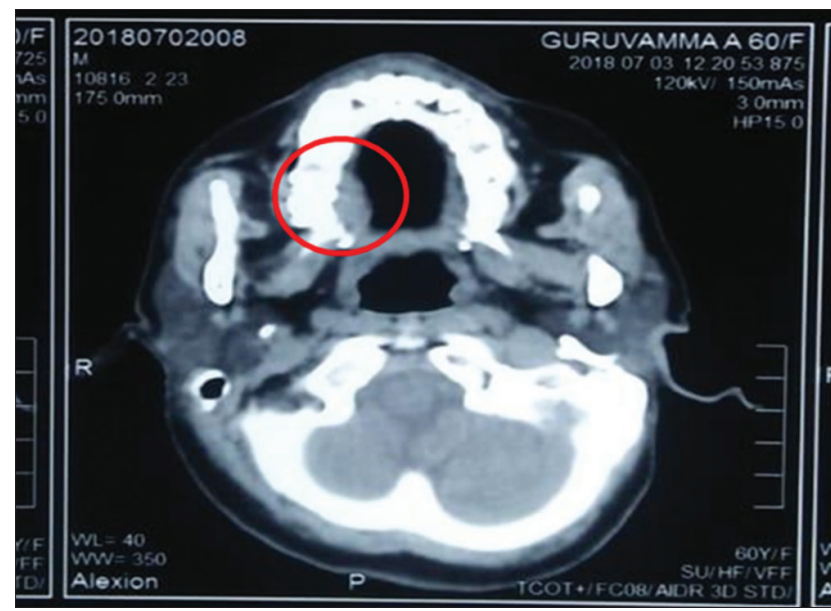

Figure 2: Computed tomography reveals a well-circumscribed lesion in the right palatal region without any signs of bony infiltration

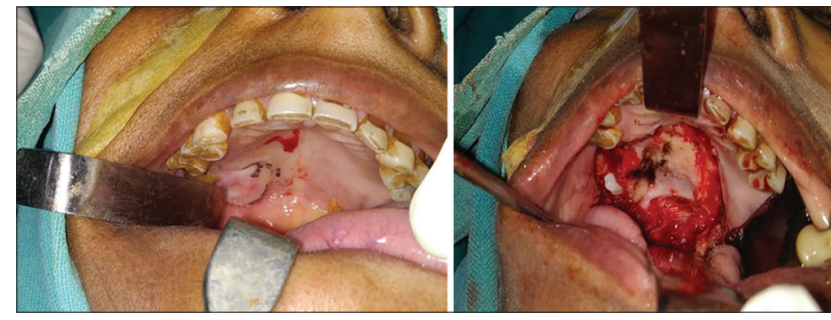

Figure 3: Marking of the lesion and wide local excision with $1 \mathrm{~cm}$ tumor-free margins of soft tissue was done under GA

\section{DISCUSSION}

Hicksand and Flaitz stated that epithelial salivary gland neoplasms are rare both in adults 

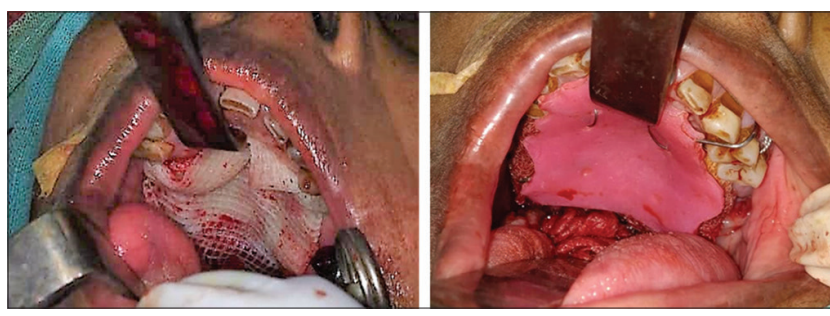

Figure 4: Placement of bactigauze followed by covering with the acrylic plate
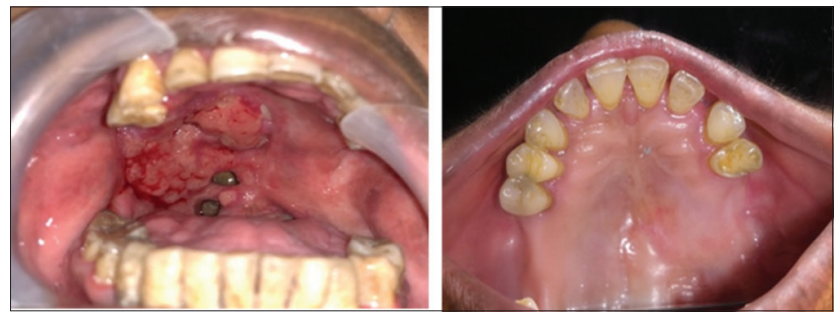

Figure 5: On follow-up, after 1 month there was granulation tissue formation and at 6 months the healing was complete and satisfactory

and children, accounting for $<3 \%$ of all head and neck tumors. $5 \%$ of these tumors occur in patients younger than 18-year-old with females mostly affected, while its occurrence in newborns is exceedingly rare. ${ }^{[11]}$ According to Baker and Malone, malignancy seen in salivary gland tumors is $50 \%$ in children and $15-25 \%$ in adults. ${ }^{[12]}$ The most common location of this tumor is parotid gland, accounting for about $60-70 \%$ of cases, followed by the minor salivary glands. MEC is about 1.5 times more prevalent in female as compared to males and is commonly seen in the third to sixth decades of life. Among minor salivary glands, the tumor shows a predilection to the hard and soft palate. ${ }^{[3]}$

Although MEC is the most common of all malignant salivary gland tumors, statistics show that malignancy of salivary glands is quite rare and intraoral involvement of minor salivary glands is even rarer. Massao and Berger first described MEC in 1924. In 1945, Stewart et al. described ME tumor as a separate pathological entity. Later, in 1991, the World Health Organization changed the name to MEC due to the metastatic nature of the tumor. ${ }^{[1]}$

As the name suggests, MEC mainly consists of mucin-producing cells and epidermoid cells. These cells are believed to arise from pluripotent reserve cells in the salivary duct system. These reserve cells may undergo neoplastic transformation at any stage of maturation and develop into immature mucin-producing cells, duct such as epidermoid cell or intermediate cells and leading to formation of MEC. ${ }^{[13]}$

Histologically these tumors show a predominance of mucous secreting cells. They appear blue in color due to the mucin filled spaces that appear blue in color through the overlying mucosa. They are partially encapsulated and contain cystic spaces filled with mucin, lined by mucussecreting, intermediate, and epidermoid cells. An intermediate grade tumor comprises solid as well as cystic areas with more predominance of solid areas. It contains a large amount of intermediate cells that can give rise to both mucous and epidermoid cells. The high-grade tumors predominantly consist of epithelial cells as the predominant cell, with very few mucinous cells. ${ }^{[13]}$

Moraes et al. suggested that low-tointermediate-grade MECs originating from intraoral minor salivary glands can be managed by wide local surgical excision that ensures tumorfree surgical margins. ${ }^{[13]}$ If there is no evidence of bony involvement, the tumor should be dissected down to the periosteum. If there is any evidence of periosteal involvement or bone erosion, removal of the involving bone is indicated. High-grade tumors require a more aggressive surgical approach with post-operative radiotherapy and chemotherapy. Low-to-intermediate-grade MECs originating from intraoral minor salivary glands have a very low recurrence rate $(<10 \%)$ and a high survival rate $(90 \%)$. Low and intermediate grade MECs have an indolent clinical course and a rare chance for metastasis. Radical neck dissection is indicated if clinical evidence of metastasis is seen. ${ }^{[14]}$

Ord and Salama documented various cases of intraoral MEC, they determined that a high percentage of these cases were low grade and usually, small in size, so adequate excision was mostly sufficient. ${ }^{[1]}$ According to Ellis, the tumor is dissected down to the periosteum to obtain adequate tumor-free margins. ${ }^{[15]}$ However, if there is any evidence of bony involvement, removal of a portion of the jaw is necessary. ${ }^{[16]}$

In literature, there are different treatment approaches for MEC. Local excision of the lesion with solid margins is generally preferred treatment method, considering that $75 \%$ of mucoepidermoid tumors are low-grade and rarely metastasise. Partial maxillectomy or palatal fenestrations are recommended for the treatment of lesions that are 
bigger and infiltrated to the bone, while for the lesions that are clinically and radiographically asymptomatic, it is recommended to treat with only soft tissue excision. ${ }^{[17,18]}$ Eversole et al. treated 17 - low and intermediate grade minor salivary gland tumor cases with excision and wide local excision. When bony erosion was present, resection was performed and the success rate was reported as $100 \% .{ }^{[19]}$

\section{CONCLUSION}

MEC is the second most seen salivary gland tumor after pleomorphic adenoma. It is important to keep MEC in mind as a definitive diagnosis for the asymptomatic, slow-growing lesions localized in the palatal region with a smooth surface. Histopathological examination following a detailed clinical and radiological examination is crucial for planning a decent treatment modality for patients' health and prognosis.

\section{REFERENCES}

1. Agrawal M, Khan TS, Sheoran J, Taranum A. Treatment of low grade mucoepidermoid carcinoma of hard palate: A conservative approach. J Oral Med Oral Surg Oral Pathol Oral Radiol 2016;2:193-5.

2. Eversole LR. Mucoepidermoid carcinoma: Review of 815 reported cases. J Oral Surg 1970;28:490-4.

3. Seifert G, Brocheriou C, Cardex A, Eveson JW. WHO international histological classification of salivary gland tumours. Path Res Pract 1990;186:55-81.

4. Boahene DO, Olsen KD, Lewis JE, Pinheiro AD, Pankratz VS, Bagniewski SM. Mucoepidermoid carcinoma of parotid gland. Arch Otolaryngol Head Neck Surg 2004;130:849-56.

5. Pires FR, Pringle GA, de Almeida OP, Chen SY. Intra-oral minor salivary gland tumors: A clinicopathological study of 546 cases. Oral Oncol 2007;43:463-70.

6. Waldron CA, El-Mofty SK, Gnepp DR. Tumors of the intraoral minor salivary glands: A demographic and histologic study of 426 cases. Oral Surg Oral Med Oral Pathol 1988;66:323-33.

7. Bell D, El-Naggar AK. Molecular heterogeneity in mucoepidermoid carcinoma: Conceptual and practical implications. Head Neck Pathol 2013;7:23-7.

8. El-Naggar AK, Lovell M, Killary AM, Clayman GL, Batsakis JG. A mucoepidermoid carcinoma of minor salivary gland with $\mathrm{t}(11 ; 19)(\mathrm{q} 21 ; \mathrm{p} 13.1)$ as the only karyotypic abnormality. Cancer Genet Cytogenet 1996;87:29-33.

9. Ellis GL, Auclair PL. Tumors of the Salivary Glands, Atlas of Tumor Pathology. $3^{\text {rd }}$ ed. Washington DC: Armed Forces Institute of Pathology; 1966

10. Thorat S, Nilesh K, Baad R, Patil P. Low grade mucoepidermoid carcinoma of the hard palate presenting as non-healing ulcer: Report and review. Int J Contemp Med Res 2016;3:3543-5.

11. Hicksand J, Flaitz C. Mucoepidermoid carcinoma of salivary glands in children and adolescents: Assessment of proliferation markers. OralOncology 2000;36:454-60.

12. Baker SR, Malone B. Salivary gland malignancies in children. Cancer 1985;55:1730-6.

13. Munhoz Ede A, Cardoso CL, Tjioe KC, Sant'ana E, Consolaro A, Damante JH, et al. Atypical clinical manifestation of mucoepidermoid carcinoma in the palate. Gen Dent 2009;57:51-3.

14. Mathew AL, Joseph BB, Sarojini DM, Premkumar P, Nair SS. Mucoepidermoid carcinoma of palate a rare entity. Clin Pract 2017;7:1009

15. Auclair PL, Ellis GL. Mucoepidermoid carcinoma. In: Ellis GL, Auclair PL, Gnepp DR, editors. Surgical Pathology of the Salivary Glands. Philadelphia, PA, USA: WB Saunders; 1991. p. 269-98.

16. Khadaroo RG, Walton JM, Ramsay JA, Hicks MJ,Archibald SD Mucoepidermoid carcinoma of the parotid gland: A rare presentation in a young child. J Pediatr Surg 1998;33:893-5.

17. Ord RA, Salama AR. Is it necessary to resect bone for lowgrade mucoepidermoid carcinoma of the palate? $\mathrm{Br} \mathrm{J}$ Oral Maxillofac Surg 2012;50:712-4.

18. Kumar AN, Nair PP, Thomas S, Raman PS, Bhambal A Mucoepidermoid carcinoma of sublingual gland: A malignant neoplasm in an uncommon region. BMJ Case Rep 2011;2:3864.

19. Eversole LR, Rovin S, Sabes WR. Mucoepidermoid carcinoma of minor salivary glands: Report of 17 cases with follow-up. J Oral Surg 1972;30:107-12. 